\title{
LEITURA DO MUNDO DE GESTANTES ADOLESCENTES: descobrindo universo vocabular baseado no círculo de cultura
}

\author{
THE WORLD READING OF PREGNANT TEENAGERS: \\ discovering the vocabulary universe based on circle of culture
}

\begin{abstract}
Glícia Mesquita Martiniano Mendonça', Maria Adelane Monteiro da Silva², Leidy Dayane Paiva de Abreu, Rebeca Sales Viana ${ }^{4}$, Francisca Alanny Araújo Rocha ${ }^{5}$, Antonio Rodrigues Ferreira Junior ${ }^{6}$
\end{abstract}

\section{RESUMO}

Objetivo: $O$ artigo objetiva revelar o universo vocabular de leitura do mundo de gestantes adolescentes, baseado nos Círculos de Cultura de Paulo Freire. Trata-se de uma pesquisa exploratória de abordagem qualitativa realizada de outubro/2012 a maio/2013 com quatorze adolescentes. Para coleta das informações utilizou-se observação participante e diário de campo nos encontros grupais. A análise dos achados se deu mediante aplicação do método de Análise Temática de Minayo. A partir do diálogo, foi possível identificar palavras do universo vocabular das adolescentes, para então propiciar conscientização crítica e rica discussão quanto a amamentação, família e grupalidade. 0 estudo permitiu conhecer as palavras geradoras do universo vocabular de adolescentes grávidas: amamentação, apoio familiar, gravidez e história de vida. Destacaram-se palavras que possibilitam melhor atuação profissional no desenvolvimento de cuidados em saúde para gestantes adolescentes.

Descritores: Gravidez na Adolescência; Educação em Saúde; Atenção Primária à Saúde.

\begin{abstract}
Objective: This article aims to expose the world of reading vocabulary universe of pregnant adolescents, based on Paulo Freire Cultural Circles. This is an exploratory research with qualitative approach carried out from October 2012 to May 2013 with fourteen teenagers. For data collection were used the participant observation and field diary. The analysis process of the information was made through thematic analysis. From the dialogue, it was possible to identify words and generative themes immersed in the universal vocabulary of these pregnant teenagers providing critical awareness and rich discussion on breastfeeding, family, and also groupality. The learning group was the center of discussions in order to provide change of attitude of adolescents. Therefore, the research study allowed know the generative words of universal vocabulary of pregnant teenagers: breastfeeding, family support, pregnancy and life story. Words stood out that enable better professional role in the development of health care for pregnant adolescents.
\end{abstract}

1 Graduada em Enfermagem pela Universidade Estadual Vale do Acaraú (UVA), Sobral, CE, Brasil.

${ }^{2}$ Doutora em Enfermagem pela Universidade Federal do Ceará (UFC), Fortaleza, CE, Brasil.

${ }^{3}$ Especialista em Gestão Ambiental pelo Instituto Federal de Educação, Ciência e Tecnologia do Ceará (IFCE), Fortaleza, CE, Brasil.

${ }^{4}$ Mestre em Gestão e Modernização Pública pela Universidade Estadual Vale do Acaraú (UVA), Sobral, $\mathrm{CE}$, Brasil.

${ }^{5}$ Mestre em Saúde da Família pela Universidade Federal do Ceará (UFC), Sobral, CE, Brasil.

${ }^{6}$ Doutor em Saúde Coletiva pela Universidade Estadual de Campinas (UNICAMP), Campinas, SP, Brasil. 


\section{Introdução}

A adolescência é uma fase sociocultural, construída historicamente a partir de critérios múltiplos que abrangem as dimensões biopsicológica, cronológica e social. Estar na adolescência é viver um período bastante conturbado na maioria das vezes, em razão das descobertas, das ideias opostas às dos pais e irmãos, formação da identidade, fase na qual as conversas envolvem namoro, brincadeiras e tabus ${ }^{1}$.

A adolescente, ao engravidar, convive com dois eventos estressores, que ocorrem sinergicamente: a adolescência e a gestação. A adolescência, por si só, implica investimentos pessoais e sociais para lidar com as mudanças físicas e emocionais, mas também com o posicionamento social, familiar e sexual. Em relação à gestação, a adolescente se vê desafiada a assumir um maior grau de independência e de responsabilidade pela provisão de cuidados com 0 desenvolvimento da gestação².

A gravidez na adolescência acontece em todas as classes sociais, mas prevalece de forma mais contundente em populações mais carentes. As dificuldades comunicativas internas à família, além da inexistência de educação sexual específica favorecem o aumento desta problemática, podendo ocasionar uma série de situações e dúvidas as quais os adolescentes não estão preparados para enfrentar, como por exemplo: interromper a gestação ou não, abandonar os estudos, mesmo que temporariamente, e assumir responsabilidades de pais quando ainda se veem como filhos ${ }^{3}$.

Este acontecimento é importante para a saúde pública em âmbito nacional, pelo impacto que causa na vida dos envolvidos na situação. Embora o país tenha melhorado significativamente o acesso ao pré-natal, a qualidade deste serviço ainda é questionável, especialmente na adolescência quando há especificidades individuais que devem ser consideradas ${ }^{4}$.

Diante desta realidade e reconhecendo que o estilo de vida da adolescente é considerado crucial para o trabalho em saúde, destacamos a necessidade de enaltecer o complexo processo que representa a gravidez na adolescência e que este exige à aplicação de tecnologias efetivas, que contemplem uma política de atenção próxima do contexto no qual estas adolescentes estão inseridas.

Partindo desta premissa, ressalta-se a etimologia do termo tecnologia que vem de techné, que significa o saber fazer, e logia que vem de logos, razão. Dessa forma, o termo é definido como a razão do saber fazer. Estendendo o conceito para o trabalho em saúde, pode-se associar a equipamentos e máquinas (tecnologia dura), a certos saberes estruturados (tecnologia leve-dura) ou a relações humanas (tecnologia leve). Sendo este último trabalhado na aplicação do círculo de cultura 5 .

Acredita-se que o uso de tecnologias contribua para a promoção e educação em saúde e manifeste nas gestantes adolescentes a oportunidade de favorecer 0 apoio mútuo, a partilha de dificuldades comuns vivenciadas por pessoas em situações semelhantes, 0 aprendizado e a adoção/manutenção de comportamentos saudáveis ${ }^{6}$. Nesse sentido, uma importante proposição está diretamente associada ao desenvolvimento pessoal e social que pode ser conquistado por meio de informação, educação para a saúde e intensificação de habilidades pessoais, capacitando a adolescente grávida para que essa exerça maior controle sobre sua saúde e a do seu futuro filho.

As experiências promissoras desencadeadas por Paulo Freire, ante a efetivação prática desse conjunto de pensamentos e atitudes, buscaram uma legítima educação como processo de inclusão e cidadania e fomentaram 0 movimento de Educação Popular. Essa educação frutífera transcende a modificação dos métodos de educar e transforma as pessoas antes passivas em partícipes na transformação da realidade, pois ao mesmo tempo educa e politiza as pessoas, despertando-as para a consciência crítica das possibilidades e dos compromissos com a construção de um mundo mais solidário7.

Reescrevendo páginas de uma história, onde todos são sujeitos e agentes de um contexto em transformação, no ideário da promoção a saúde, com justiça e humanização da sociedade, os Círculos de Cultura adentram as ações de Educação em Saúde, com intuito de fortalecer a ação de todos que fazem parte da troca de experiências, por fortalecer processos de empowerment dos profissionais e dos usuários no exercício de sua cidadania como sujeitos de uma história em transformação ${ }^{7}$.

A utilização efetiva do Círculo de Cultura como estratégia de Educação em Saúde tem sido experimentada. Além de proporcionar a exploração e discussão de diversos temas com adolescentes, também, permite diálogo com este público, possibilitando a autonomia dos participantes e a reflexão crítica da realidade com o compromisso político para sua transformação. A rigor, não se ensina, se aprende em reciprocidade de consciências; não há um professor, há um coordenador, que tem por função dar as informações solicitadas pelos respectivos participantes e propiciar condições favoráveis à dinâmica do grupo, reduzindo ao mínimo sua intervenção direta no curso do diálogo . 
Freire realizou pequenas pesquisas de construção do conhecimento da realidade local com o objetivo de envolver-se com o trabalho de alfabetização nas comunidades. Esta primeira etapa pedagógica do método foi denominada por Freire com diversos termos semelhantes: "levantamento do universo vocabular" (em Educação como Prática da Liberdade), "descoberta do universo vocabular" (em Conscientização), "pesquisa do universo vocabular" (em Conscientização e Alfabetização), "investigação do universo temático" (em Pedagogia do Oprimido) ${ }^{9}$. O objetivo da pesquisa do universo vocabular é de impressionar quanto à maneira como uma realidade social existia na vida e no pensamento dos seus participantes. É a descoberta coletiva da vida por meio da fala, do mundo através da palavra.

Portanto, este estudo busca levantar o universo vocabular a partir da leitura do mundo de adolescentes grávidas de um grupo de gestantes adolescentes com base nos Círculos de Cultura de Paulo Freire.

\section{Metodologia}

Trata-se de uma pesquisa exploratória com abordagem qualitativa ${ }^{10}$, que adota como perspectiva promover uma familiarização com o problema investigado, com vistas a torná-lo mais explícito ou a construir hipóteses ${ }^{11}$.

Refere-se à primeira etapa do Círculo de Cultura do método Paulo Freire ${ }^{12}$, o levantamento do universo vocabular, no processo de implantação de um grupo de 20 gestantes adolescentes em um Centro de Saúde da Família (CSF) de município polo no norte do Ceará, no período de outubro de 2012 a maio de 2013.

Para ter acesso à população que iria compor os participantes desta pesquisa, inicialmente, foi realizada visita ao CSF do estudo, para conhecimento da área, contato inicial com a equipe de saúde para verificação dos prontuários das gestantes e informações quanto aos dias e horários de consulta pré-natal. Nessa oportunidade, foram esclarecidos os objetivos do estudo para a equipe do serviço.

A seleção dos participantes atendeu aos seguintes critérios de inclusão: ser adolescente conforme o Ministério da Saúde, na faixa etária entre 10 e 19 anos, 11 meses e 29 dias; estar em processo gravídico durante o período do estudo; apresentar condições física e psíquica para participar da pesquisa.

Ao considerar que se trata de pesquisa qualitativa, esta articula questões de ordem subjetiva como raízes culturais, sentimentos, emoções, comportamentos, reflexões e colocações pessoais, discussões e síntese resultante da produção coletiva $^{13}$. Neste sentido, foram utilizados para coleta de informações nas reuniões mensais: a observação participante, o registro em diário de campo e a utilização de gravador. As informações de cada encontro foram transcritas na íntegra mediante as falas captadas e passaram por avaliação dos profissionais de saúde que acompanhavam as gestantes durante o pré-natal. Buscou-se com isso, confirmação das temáticas comumente verbalizadas pelo grupo, evitando inferências dos pesquisadores.

Para seu criador, o Círculo de Cultura, era o espaço em que dialogicamente se ensinava e se aprendia que não havia espaço para transferência de conhecimento, mas a construção do saber do educando com suas hipóteses de leitura de mundo. Ele propicia um ambiente dialógico, em grupos específicos, onde há interação entre os participantes e permite a percepção de situações vivenciadas por estes, por meio do universo vocabular utilizado na comunicação ${ }^{12}$.

A primeira etapa da investigação dos "temas geradores" ou da "temática significativa" de uma determinada área inicia pelas fontes secundárias, universo vocabular. Essa investigação se dá por meio de conversas informais com os moradores da região sobre o objetivo de sua presença no local durante uma reunião. O objeto fundamental dessa primeira etapa é estudar a percepção e o núcleo de contradição dos indivíduos da área. Essas contradições não são mais que "situações limites". Esse conjunto de contradições ainda não é suficiente para a estruturação do conteúdo programático da ação educativa. Segundo Freire "esta visão é deles ainda, e não a dos indivíduos em face de sua realidade"14.

A fase seguinte da investigação começa quando os investigadores, a partir dos dados que colheram, chegam à apreensão daquele conjunto de situações-limites. Em equipe, escolheram algumas dessas situações ou contradições para serem codificadas. Preparadas as codificações os investigadores iniciam a terceira fase com a decodificação do material elaborado. Nesta, voltam à área para inaugurar os diálogos decodificadores, nos "círculos de investigação temática" ou "círculos de cultura". Feito isso inicia a quarta fase, quando os investigadores, terminadas as decodificações nos círculos, dão começo ao estudo sistemático e interdisciplinar de seus achados. Os investigadores a princípio ouviram todas as gravações, as decodificações e os comentários elaborados pelos observadores feitas nos "círculos de investigação"12.

Desse modo, as atividades desenvolvidas no Círculo de Cultura são momentos de encontro entre a vivência prática e a teoria em que a intenção dada à direção pedagógica se materializa na concretização da teoria em vida, no 
existenciar-se. Importante destacar que a seleção/organização do conteúdo programático assume papel de destaque e deve se dar a partir de uma situação presente, existencial e concreta em que se propõe, por meio das contradições nela presentes, sua problematização na busca do universo temático e seu conjunto dos temas geradores. A investigação/ busca dos temas geradores implica, necessariamente, uma metodologia que não pode contradizer a dialogicidade da educação libertadora. Daí que seja igualmente dialógica ${ }^{14}$.

Apresentamos as etapas do método Paulo Freire ${ }^{12}$ para melhor entendimento e detalharmos os seus desdobramentos, no entanto, como prevalece o sentido dialético em toda a sua extensão, essas etapas se entrelaçam e se misturam; não são estanques. Possuem, no entanto, uma ordem cronológica para que o processo de ensinoaprendizagem aconteça de maneira completa e significativa tanto para quem aprende, quanto para quem ensina.

Neste estudo, a descrição e organização dos resultados constaram da transcrição das informações coletadas, com registros de falas na íntegra, ordenadas mediante narração e discussão, permitindo assim, a análise das informações coletadas mediante os pressupostos do método Paulo Freire ${ }^{12}$ e a Análise Temática ${ }^{10}$.

A técnica de Análise Temática ${ }^{10}$ consiste em descobrir os núcleos de sentido que compõem uma comunicação, cuja presença ou frequência signifiquem alguma coisa para o objeto analítico visado. Tradicionalmente, a análise temática era feita pela contagem de frequência das unidades de significação, definindo o caráter do discurso. Para uma análise de significados, a presença de determinados temas denota estruturas de relevância, valores de referência e modelos de comportamento presentes ou subjacentes no discurso.

As integrantes foram elucidadas sobre os objetivos deste trabalho, de forma adequada à compreensão, a fim de convidá-las a participarem do estudo. Logo, foi garantido o sigilo e anonimato, no intuito de preservá-las em sua identidade e privacidade, considerando o que preconiza a Resolução 466/12, do Conselho Nacional de Saúde, sobre diretrizes e normas regulamentadoras que tratam de pesquisas com seres humanos15. Para a garantia do anonimato das participantes utilizou-se nomes de espécies de aves para identificá-las: Andorinha, Gaivota, Garça, Sabiá, entre outros.

O estudo foi submetido ao Comitê de Ética e Pesquisa da Universidade Estadual Vale do Acaraú, obtendo aprovação, conforme Parecer n 19748, datado de 09 de maio de 2012.

\section{Resultados e Discussão}

A base que fundamenta o Círculo de Cultura, numa visão antropológica Freiriana, é o diálogo. É na palavra pronunciada, que os participantes se fazem ao fazer e refazer o próprio mundo, a ação educativa ${ }^{16}$.

É necessária esta discussão à medida que acreditamos que conhecer o universo vocabular das adolescentes, para procedermos com a tematização em grupo, proporcionará um envolvimento e estabelecimento de vínculo mais efetivo entre pesquisador/facilitador e adolescente, além de favorecer a obtenção de resultados positivos a partir de fatores terapêuticos envolvidos.

Para Freire esse momento é essencial para concretização de cada uma das fases do Método, pois consiste no levantamento de vocábulos do universo das participantes do grupo a desenvolver-se. Ademais refere-se a uma pesquisa que permite uma aproximação entre educador e educando numa relação mais informal, porém carregada de sentimentos e emoções. É igualmente importante para o contato mais aproximado com a linguagem, com os falares típicos do povo, com sua cultura ${ }^{12}$.

\section{Conhecendo as adolescentes}

Para o desenvolvimento do trabalho com a aplicação do Círculo de Cultura, é essencial que o pesquisador esteja atento para o que se fala. As conversas, as entrevistas e as discussões, tudo, intrinsecamente, relacionado com a vida daquelas pessoas que participam ${ }^{12}$.

Partindo desses pressupostos de Freire, identificamos vinte gestantes adolescentes que atendiam aos critérios de inclusão do estudo, com idades que variavam de 14 a 19 anos. Onze viviam em união estável, cinco moravam com os pais e quatro eram casadas, onze estavam desempregadas e a renda provinha de seus parceiros, vivendo com menos de um salário mínimo, por meio de trabalho informal.

Das adolescentes, oito estudam, cinco no ensino médio e três no ensino fundamental; e seis pararam de estudar. Dez são primigestas, com idade gestacional entre 16 e 36 semanas e uma adolescente relatou já ter sofrido um aborto. 
Nas consultas de pré-natal, doze fizeram de 1 a 5 consultas e oito gestantes tinham feito seis consultas. Dez das entrevistadas estavam no segundo trimestre gestacional.

Freire propõe, como primeira situação a ser debatida no processo de alfabetização de adultos no Círculo de Cultura, o entendimento do ser humano como um ser que transforma a realidade pelo papel ativo que desempenha nela e com ela ${ }^{17}$. Isto porque é com seu trabalho que o ser humano vem historicamente alterando o mundo natural de acordo com suas necessidades, e estas mediações propiciam não apenas a emergência da transformação, mas o processo de conhecimento, que é cultural.

Em seguida, definiram-se as estratégias em que as informações obtidas por intermédio da observação participante e das conversas informais permitiram o levantamento do universo vocabular das adolescentes. Observou-se que o grupo estava inserido em uma realidade que envolvia palavras relacionadas com o contexto da saúde da mulher, do bebê e da adolescência ${ }^{12}$.

\section{Leitura do mundo das adolescentes}

A leitura do mundo é a primeira etapa do Método Paulo Freire ${ }^{12}$. Por meio dessa leitura se torna possível mergulhar no universo das adolescentes buscando conhecer suas vivências e anseios, praticando o estudo da realidade. Torna possível o diálogo, sem o qual a leitura do mundo torna-se incompleta e insuficiente. As falas reveladas a seguir representam o universo da população em questão, as quais direcionaram a discussão, sendo escolhidas as que potencializaram otimização do diálogo no grupo de gestantes.

Durante os encontros revelaram a ansiedade em relação à 'amamentação' e dúvidas quanto ao processo, sendo esta a primeira palavra geradora encontrada. Estudos evidenciam não haver associação entre o desmame e a primiparidade. Contudo, verifica-se que as mães primíparas são as que menos amamentam exclusivamente ao seio, fazendo-se necessário o estabelecimento de um olhar mais atento da equipe de saúde para estas mulheres, aliado a uma educação no pré-natal mais qualificada e fundamentada em uma escuta acolhedora. Estas ações podem se configurar em estratégias a fim de capacitá-las e empoderá-las para que resistam às pressões sociais do desmame ${ }^{18-20}$.

O universo vocabular das adolescentes envolto aos mitos e dúvidas perpassados no âmbito familiar primário relacionados à amamentação, possibilitam a observação da palavra geradora para a segunda fase do Método Paulo Freire $^{12}$, que integra a escolha dos temas levantados do universo vocabular das pesquisadas.

A amamentação e seu incentivo ainda são desafios na sociedade. Muitas mães e avós não criaram seus filhos exclusivamente no seio, utilizando a introdução de chá e leite artificial associado com cereal nos primeiros dias de vida da criança. Por conta disso, estas apresentam resistência à amamentação exclusiva, valorizando as dificuldades dessa prática, no intuito de "proteger" suas filhas/noras ${ }^{18}$. $O$ trabalho em grupo quanto à temática amamentação, proporciona o esclarecimento e o incentivo necessário à amamentação exclusiva, munindo as adolescentes de argumentos sobre os benefícios obtidos para a mãe e o bebê, o que possibilita melhor tomada de decisão destas acerca do ato de alimentar o filho.

"Nunca amamentei e não sei como vou fazer, minha mãe falou que nunca me amamentou"(Andorinha)

Quanto ao desejo do apoio da família e do companheiro no processo gravídico, os discursos correlacionavam o bem-estar materno e fetal ao ambiente familiar agradável e equilibrado, verificado pela emoção suscitadas nas falas. As relações vivenciadas no entorno intra e extrafamiliar, revelaram a palavra geradora 'apoio familiar' para discussão em grupo, disparando no coordenador/animador do Círculo de Cultura a necessidade de olhar essas gestantes para além do processo gravídico e, percebê-las como integrantes de relações interpessoais que exercem influência sobre a gravidezparto-puerpério.

"Queria que meu namorado e meus pais me dessem mais atenção e ao meu filho também, estamos precisando agora. É importante né o apoio da família para meu filho nascer bem?"(Gaivota)

A família e o companheiro se mostram importantes como fonte de apoio para a gestante adolescente, pois ampliam o fortalecimento dos vínculos, minorando a ansiedade, medo e dúvida acerca do processo gravídico e futuro papel materno ${ }^{21-22}$. 
E em consonância com as singularidades dos adolescentes, as gestantes expuseram a importância da implantação de um grupo de gestantes destinado especificamente ao público adolescente.

"Eu acho muito importante ter um grupo só nosso. "(Sabiá)

"Eu não me sinto bem no grupo de todas as gestantes, tenho dúvidas que fico com vergonha de falar porque elas tudo já sabe, porque já tiveram outros filhos. "(Garça)

A discussão do aprendizado em grupo é associada à criação de um espaço de diálogo onde as participantes têm as mesmas características, as mesmas dúvidas e anseios quanto à gravidez, ampliando a empatia. Neste cenário a formação de vínculo pode se tornar maior do que em grupos mistos, com gestantes adultas e adolescentes.

Quanto ao aprendizado em grupo, as adolescentes demonstraram desejo em aprender assuntos relacionados à 'gravidez' e que consideram importantes para o seu autocuidado e sua autonomização no processo gravídico, gerando a terceira palavra geradora.

"Tenho vontade de saber sobre a minha saúde que também é importante." (Cegonha)

"Queria aprender sobre os medos e dores que nos dá quando a gente tá grávida."(Águia)

O Ministério da Saúde preconiza a realização de práticas educativas individuais e coletivas durante a conduta do pré-natal de baixo-risco, enfatizando que os grupos educativos para adolescentes devem ser exclusivos desta faixa etária, onde se deve abordar temas de interesse das participantes. Sugere ainda, para uma maior obtenção de resultados, que estes grupos sejam divididos em faixas de 10-14 anos e de 15-19 anos ${ }^{23}$.

A formação de grupos com gestantes adolescentes se constitui em uma oportunidade preciosa para os profissionais da saúde discutirem assuntos importantes para este público, pois ao se apoiarem em iguais, os adolescentes conseguem participar de forma efetiva das construções coletivas, com impacto em sua saúde individual ${ }^{24}$.

Na perspectiva do Método Paulo Freire, o Círculo de Cultura, é um espaço que dialogicamente se ensina e se aprende, onde não há espaços para transferência de conhecimentos, mas para a construção de um saber. Portanto, essas gestantes adolescentes têm muito a contribuir com o grupo, pois serão disparadoras de discussão e poderão envolver todos os participantes nestes momentos de dialogicidade e enriquecimento mútuo ${ }^{14}$.

Os diálogos emergidos no grupo, possibilitaram a percepção de sentimentos, valores e sonhos das adolescentes, explicitando a quarta palavra geradora: história de vida. Além de sentimentos de alegria e expectativa pela gravidez, as adolescentes expressam receios e angústias naturais a essa fase. Seus medos estão ligados a questionamentos como: estarei preparada para receber a criança que vai nascer? Saberei cuidar dela? Como será o parto? Sentirei dor? Enfrentarei preconceitos por ser mãe tão jovem? Serei aceita pela Igreja que frequento? Entre os valores destaca-se a noção de responsabilidade, muitas vezes desafiada diante de situações difíceis como enfrentar a oposição da mãe à união com o pai da criança, estar com o parceiro aprisionado, ou ter que percorrer um longo trajeto para frequentar as reuniões de grupo. Seus sonhos, parecem mais integrados a uma visão de futuro ligada a maternidade, mas não só a isso. Elas também sonham em ser universitárias, estudar, ter uma profissão de sucesso.

Compreende-se que o educar na saúde também precisa transcender o sujeito, entender sua intimidade para com isso trabalhar as relações que são indispensáveis para efetivar o cuidado. Neste âmbito, conhecer o universo vocabular de adolescentes grávidas, pode propiciar melhora no cuidado implementado, especialmente ao considerar as palavras geradoras deste universo: amamentação; apoio familiar; gravidez; história de vida.

Para Paulo Freire ${ }^{12}$ é preciso construir um conhecimento autêntico (que partisse da realidade brasileira, que desse respostas aos problemas vividos pelo povo) e orgânico (em estreita relação com a realidade vivida, buscando transformála). Daí o papel da educação é, então, o da conscientização e o conhecimento construído por meio do processo educativo teria a função de motivador e impulsionador da ação transformadora. Nessa perspectiva, o ser humano deveria entender a realidade como modificável e a si mesmo como capaz de modificá-la.

É a "leitura do mundo" que vai possibilitando a decifração cada vez mais crítica da ou das "situações-limites". É preciso, porém, fazer da leitura um exercício dialógico entre os indivíduos com respeito ao saber individual e a partir desta experiência, realizar construções positivas para os envolvidos ${ }^{12}$. 


\section{Considerações Finais}

Este estudo propôs o levantamento do universo vocabular por intermédio da leitura do mundo de gestantes adolescentes, e esse mergulho permitiu interação coletiva no processo, ajudando a definir o ponto de partida para que o tema gerador desse grupo pudesse ser desenvolvido. Salienta-se que esse processo está vinculado a ideia de interdisciplinaridade e é subjacente à noção integral de cuidado e aos desafios de agregar conhecimento, transformação social e 0 aprendizado.

Amamentação, apoio familiar, gravidez e história de vida se apresentaram como pilares do universo vocabular das gestantes adolescentes, denotando áreas específicas que merecem ser discutidas com os profissionais que as acompanham no processo gravídico.

Foi possível observar que as adolescentes inicialmente se mostraram tímidas e pouco responsivas neste processo do círculo de cultura, no entanto paulatinamente a experiência foi aprimorada durante o exercício da prática e 0 aprofundamento teórico do método aplicado.

As limitações do estudo estão pautadas nas especificidades do cenário, porém são as experiências individuais valoradas que permitem uma troca dialógica de saberes, potencializando o cuidado em saúde às adolescentes que engravidam nos mais diversos e complexos territórios.

O desenvolvimento desta atividade possibilitou construir conhecimentos, por gerar um cenário onde os envolvidos foram sujeitos de trabalho comum, ao dialogar acerca dos pensamentos freireanos e da sua aplicabilidade, de vivenciar desafios análogos em um mesmo espaço de discussão.

\section{Referências}

1. Duberg A, Möller M, Sunvisson H. "I feel free": Experiences of a dance intervention for adolescent girls with internalizing problems. Int J Qual Stud Health Well-being. 2016; 11:31946.

2. Wall-Wieler E, Roos LL, Nickel NC. Teenage pregnancy: the impact of maternal adolescent childbearing and older sister's teenage pregnancy on a younger sister. BMC Pregnancy Childbirth. 2016;16(1):120.

3. Santos AG, Gomes KRO, Gama SGN, Silva JMN. Pré-natal e parto: diferenças entre as adolescentes e jovens usuárias da saúde suplementar e as do Sistema Único de Saúde. Adolesc. Saude, Rio de Janeiro. 2015; 12 (4): 19-28.

4. Viellas EF, Domingues RMSM, Dias MAB, Gama SGN, Theme Filha MM, Costa JV, et al. Assistência pré-natal no Brasil. Cad. Saúde Pública, Rio de Janeiro. 2014; 30(Sup):S85-S100.

5. Merhy EE. Em busca de ferramentas analisadoras das tecnologias em saúde: a informação e o dia a dia de um serviço, interrogando e gerindo trabalho em saúde. In: Merhy EE, Onoko, R, organizadores. Agir em Saúde: um desafio para o público. $2^{\text {a }}$ ed. São Paulo (SP): Hucitec; 2002. 113-50

6. Mendonça GMM, Abreu LDP, Rocha FAA, Silva MAM. Abordagem grupal como estratégia de cuidado no pré-natal. SANARE, Sobral. 2014; 13(2): 78-85.

7. Monteiro EMLM. (Re)Construção de Ações de Educação em Saúde a partir de Círculos de Cultura: experiência participativa com enfermeiras do PSF do Recife/PE [Tese]. Fortaleza: Programa de Pós-graduação em Enfermagem da Faculdade de Farmácia, Odontologia e Enfermagem da Universidade Federal do Ceará; 2007. $179 f$.

8. Abreu LDP, Mendonça GMM, Andrade AC, Oliveira GR, Aurélio DO, Rocha FAA, et al. Abordagem educativa utilizando os Círculos de Cultura de Paulo Freire: experiência de acadêmicos de enfermagem no "Grupo Adolescer". Adolesc. Saude, Rio de Janeiro. 2013; 10(4): 66-70.

9. Brandão CR. O que é o método Paulo Freire. 32a ed. São Paulo: Brasiliense; 2011.

10. Minayo MCS. O desafio do conhecimento: pesquisa qualitativa em saúde. 13a ed. São Paulo: Hucitec; 2013.

11. Métodos de pesquisa / [organizado por] Tatiana Engel Gerhardt e Denise Tolfo Silveira; coordenado pela Universidade Aberta do Brasil - UAB/UFRGS e pelo Curso de Graduação Tecnológica - Planejamento e Gestão para o Desenvolvimento Rural da SEAD/UFRGS. - Porto Alegre: Editora da UFRGS, 2009.

12. Freire P. Extensão ou comunicação. $5^{\text {a }}$ ed. Rio de Janeiro: Paz e Terra; 1982.

13. Goertz G, Mahoney J. A tale of two cultures: qualitative and quantitative research in the social sciences. Princenton: Princenton University Press; 2012. 
14. Freire P. Pedagogia do oprimido. $17^{\mathrm{a}}$ ed. Rio de Janeiro: Paz e Terra; 2011.

15. Ministério da Saúde (BR). Conselho Nacional de Saúde. Comissão Nacional de Ética em Pesquisa - CONEP. Resolução n 466/12: sobre pesquisas envolvendo seres humanos. Brasília; 2012.

16. Marinho ARB. O círculo de cultura no contexto das novas tecnologias de informação. Uma ação comunicativa para as políticas públicas. Anuário Unesco/Metodista de Comunicação Regional. 2014; 18(18): 77-88.

17. Brandão Neto W, Silva ARS; Almeida Filho AJ, Lima LS, Aquino JM, Monteiro EMLM. Intervenção educativa sobre violência com adolescentes: possibilidade para a enfermagem no contexto escolar. Esc Anna Nery. 2014;18(2):195-201. 18. Assis ELA, Nodari PRG, Silva RB, Aleixo MLM. Dificuldades enfrentadas por puérperas primíparas durante 0 ao aleitamento materno exclusivo. Rev Elet Gestão \& Saúde. 2014; 5(3): 808-19.

19. Teixeira MM, Vasconcelos VM, Silva DMA, Martins EMCS, Martins MC, Frota MA. Percepções de primíparas sobre orientações no pré-natal acerca do aleitamento materno. Rev Rene. 2013; 14(1):179-86.

20. Campos AMS, Chaoul CO, Carmona EV, Higa R, Vale IN. Prática de aleitamento materno exclusivo informado pela mãe e oferta de líquidos aos seus filhos. Rev. Latino-Am. Enfermagem. 2015;23(2):283-90.

21. Bordignon SS, Cruz VD, Harter J, Meincke SMK, Carraro TE, Collet N. Participação paterna e reação familiar frente à gravidez na adolescência. Rev enferm UFPE on line., Recife. 2013; 7(6):4459-65.

22. Santos CC, Wilhelm LA, Alves CN, C'remonese L, Castiglioni CM, Venturini L, et al. A vivência da gravidez na adolescência no âmbito familiar e social. Rev Enferm UFSM. 2014 Jan/Mar; 4(1):105-112.

23. Ministério da Saúde (BR). Secretaria de Atenção à Saúde. Departamento de Ações Programáticas Estratégicas. Orientações básicas de atenção integral à saúde de adolescentes nas escolas e unidades básicas de saúde. Brasilia: Ministério da Saúde; 2013.

24. Queiroz LS, Cerqueira CO, Mendonça AVM. Implantação de um grupo de gestantes adolescentes: relatos das ações de informação, educação e comunicação para a promoção da saúde. Tempus, actas de saúde colet, Brasília. 2015; 9(1): 145-53.

\section{Glícia Mesquita Martiniano Mendonça}

Endereço para correspondência - Av. Dr. Silas Munguba, $n^{\circ}$ : 1700, Bairro: Campus do Itaperi, CEP: 60714-903, Fortaleza, CE, Brasil.

E-mail: glicia_martiniano@hotmail.com Lattes: http://lattes.cnpq.br/0501255584870455

Maria Adelane Monteiro da Silva - adelanemonteiro@hotmail.com Leidy Dayane Paiva de Abreu - dayannepaiva@hotmail.com

Rebeca Sales Viana - rebecasalesviana@gmail.com

Francisca Alanny Araújo Rocha - alannyrocha2009@hotmail.com Antonio Rodrigues Ferreira Junior - arodrigues.junior@uece.br

\section{Enviado em 05 de agosto de 2016. Aceito em 27 de março de 2017.}

